\title{
Design and Finite Element Analysis of Domestic LPG Cylinder using ANSYS Workbench
}

\author{
C. Sai Kiran ${ }^{1}$ and J. Sruthi ${ }^{2}$ \\ ${ }^{1}$ Asst. Professor, CVR College of Engineering/Mechanical Department, Hyderabad, India \\ Email: csaikiran001@gmail.com \\ ${ }^{2}$ Asst. Professor, CVR College of Engineering/ Mechanical Department, Hyderabad, India \\ Email: sruthij02@gmail.com
}

\begin{abstract}
In this paper, domestic LPG cylinder was designed and analyzed, which can be used for storing the fluids at a higher pressure. LPG cylinder is one of the kind of pressure vessel that stores pressurised gases. LPG cylinder material should have high tensile and compressive strength for withstanding the high pressure of the gases. The purpose of this work is to design the LPG cylinder for safe, easy operation and able to resist the burst pressure or different loading conditions by studying the total deformation and von-mises stress of the cylinder, which are useful for assessing the safety and life prediction of the LPG cylinder. A detailed finite element analysis of LPG cylinder is performed using ANSYS and these analyses helps to predict the burst pressure of the LPG cylinder when an internal load acts on it.
\end{abstract}

Index Terms: LPG cylinder, Pressure vessel, Von-mises stress, ANSYS.

\section{INTRODUCTION}

Abbreviation of LPG is liquefied petroleum gas. LPG consists of hydrocarbons, butane and propane. The LPG is extracted from refining of the crude oil. It is called as liquefied petroleum gas because this gas liquefy under moderate pressure and it is readily vaporize upon the release of pressure. LPG exists in gaseous state at normal atmospheric pressure and at normal room temperature. LPG is a colorless, non-toxic and odorless gas. Therefore, a stench agent like ethyl mercaptan is added to the gas for leak detection. Ethyl mercaptan is selected because it has same boiling point as LPG, non-corrosive and has low Sulphur content. LPG is stored in a cylinder as it is a flammable gas and which can be used as cooking gas in household. The average weight of the cylinder is $14.2 \mathrm{kgs}$.

Alok et al. [1] has created the LPG model in CATIA VR R20 software and performed a finite element analysis of LPG cylinder which is subjected to an internal pressure, by taking three different materials from ANSYS software. The values estimated by ANSYS are compared with the classical mathematical formulations. The LPG cylinder calculations are performed to determine the cylinder weight and the material with the least weight is selected for new LPG cylinder.

Bandhavi et al. [2] has performed a finite element analysis of LPG cylinders made of steel and fibre reinforced plastic to reduce the weight of the LPG cylinder using ANSYS software, which is subjected to the internal pressure. Stress and deformations inside the LPG cylinders are observed due to internal pressure. The results of deformations and stress on the LPG cylinders are compared with the analytical solutions for validating the software and the created model. The obtained values are within the limits.

Moketla et al. [3] has designed a LPG cylinder and performed a burst pressure test for $3 \mathrm{Mpa}$. The thickness of $3.5 \mathrm{~mm}$ in the LPG cylinder has been established by using Abaqus software based finite element analysis. The LPG modelling and finite element simulations were carried out by using Abaqus software. The von-mises stress contour plot of LPG cylinder is generated after static finite element analysis. The maximum operating pressure of the LPG cylinder is $1.3 \mathrm{Mpa}$ and the burst pressure test was performed at $3 \mathrm{Mpa}$ by considering a factor of safety.

Somaiah et al. [4] has elaborated the design procedure of LPG cylinder by alternative materials used for manufacturing. The reduction of weight in the conventional LPG cylinder is done by replacing the material with glass fibre reinforced plastic composites. A glass fibre reinforced polymer material is used as the material for the LPG cylinder because it doesn't explode due to porosity formation in the material. Steel cylinders are manufactured with the welded joint, but the composite cylinders manufacturing has a single joint because they are manufactured by using filament winding technique. The factor of safety for the composite cylinder is considered as 2.5 and the internal pressure is $0.3 \mathrm{Mpa}$. The design stress values are within the limits and the life time of Fibre reinforced plastic cylinder is double than that of the steel cylinder because of lesser corrosion rate. The developed stress is within the safe limits and a weight saving of $75 \%$ is achieved when compared to metallic cylinders. Therefore, the material selected for the LPG cylinder is cost effective and safe in operation.

Gopi et al. [5] has designed and performed the finite element analysis of LPG cylinders which are made up of steel and glass fibre reinforcement plastic. The longitudinal stress, hoop stress and von-mises stress are calculated manually and are compared with the analytical method to know the error percentage for validating the software and LPG model. The optimum thickness of the cylinder is calculated by varying the thickness as $1.5,1.53$ and 1.54 $\mathrm{mm}$ and the optimum value for the thickness is $1.53 \mathrm{~mm}$ based on the von-mises stress contour plot values.

Krishna et al. [6] has designed a LPG cylinder and performed finite element analysis on the LPG cylinder by using three different materials. The total displacement and von-mises stress values for different LPG cylinder materials is compared and best suited material is selected. 
Ashok et al. [7] has modelled a LPG cylinder and performed a finite element analysis of LPG cylinder, which is subjected to an internal pressure. The total displacement and von-mises stress values are compared with the different LPG cylinders. The finite element method and the analytical method values compared with each other and the values of the stress and deformations are found to be within the limits.

Laxmikant et al. [8] has designed a LPG cylinder using PROE software and finite element analysis is performed using ANSYS software by applying boundary and loading conditions on the LPG cylinder. The total deformation and von-mises stress values are observed to determine the burst pressure of the LPG cylinder. The manual calculations are compared with finite element analysis values obtained from ANSYS software.

\section{A. Liquefied Petroleum Gas (LPG) Cylinders}

LPG is supplied in pressurized cylinders to keep it liquefied. LP gas inside the cylinder is in two states of matter i.e, liquid and vapour. The liquid is in the bottom portion of the cylinder and the vapour is in the uppermost part of the cylinder. At normal room temperature for withdrawing of the gas, when we open the valve, the pressure inside the cylinder is dropped and the liquid reverts to gas. Therefore, the LPG cylinder must be capable to withstand the internal pressure of the fluid for longer time. The LPG cylinder must be as per IS 3169 standards to withstand the internal pressure of the fluid.

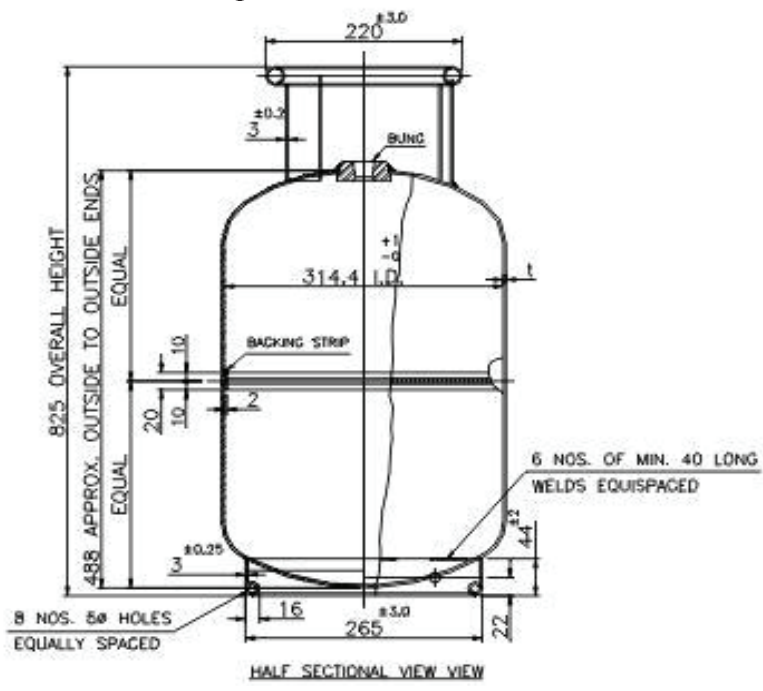

Figure 1. LPG cylinder as per IS 3196 standards

The different parts of the LPG cylinder are represented in Fig.2. The main parts of a LPG cylinder are given below:

1. Collar/Valve Protection Ring.

2. Cylinder Valve.

3. Cylinder Bung or Valve Pad.

4. Top dome.

5. Cylindrical body.

6. Bottom Dome.

7. Base Ring or Foot Ring.

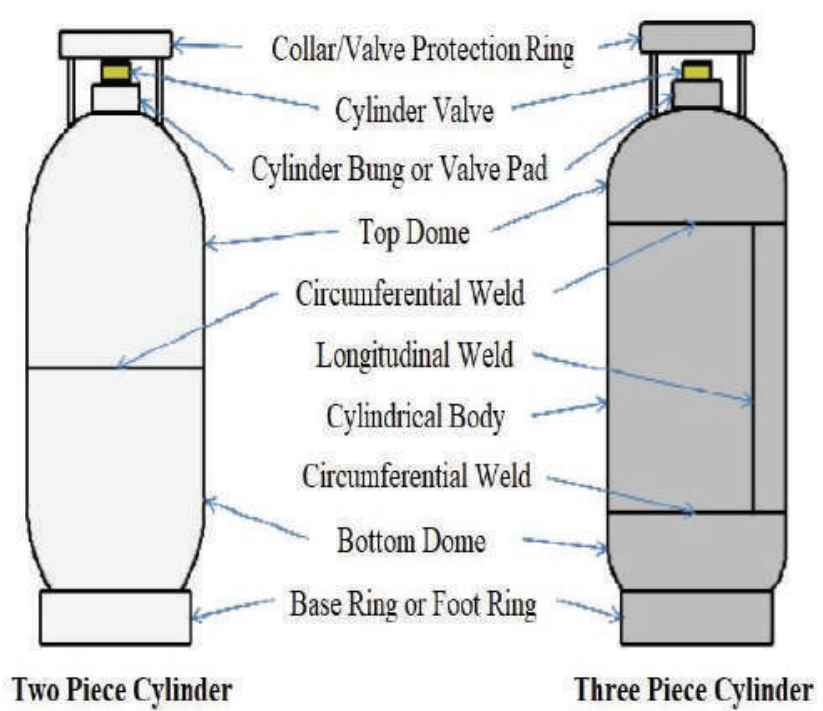

Figure 2. Different parts of the LPG cylinder

\section{B. Manufacturing of LPG Cylinder}

The manufacturing of domestic LPG cylinder is done either in two-piece construction or three-piece construction. In the two-piece construction, the fabrication of the cylinders is done by welding of the two domes circumferentially with the circumferential weld. In the threepiece construction, the two half's of the cylindrical body is joined by longitudinal weld and the two dome ends are joined together by circumferential weld. The different types of dome ends are tori-spherical, semi-ellipsoidal and hemispherical as shown in Fig.3.

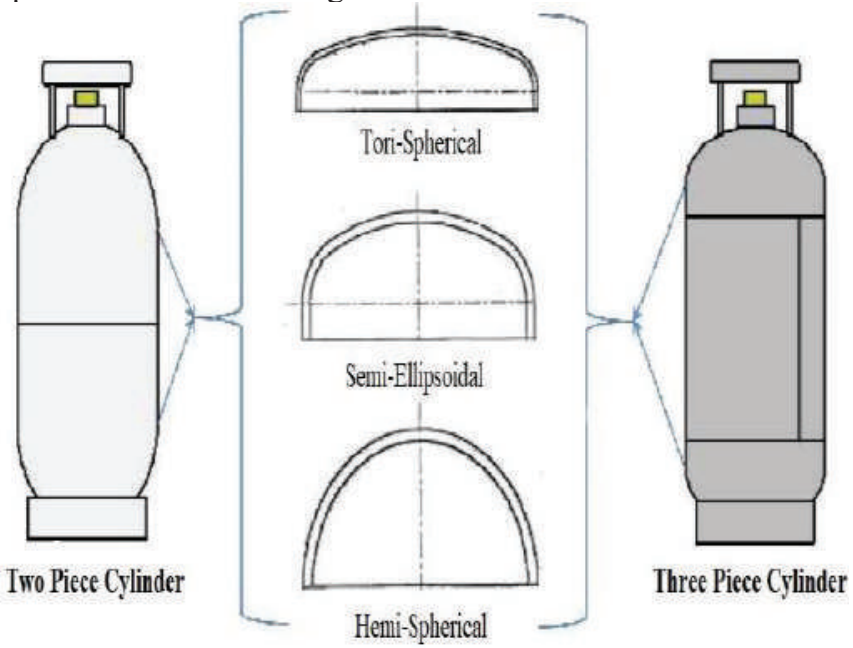

Figure 3. Different dome shapes of the LPG cylinder

\section{LPG Cylinder Material}

LPG cylinders are usually made of materials that are very strong and are suitable for withstanding the internal pressure. Therefore, low carbon steel is selected as material for LPG cylinder because of its life durability, light weight and safe operations. The material properties of the low carbon steel are shown in the Table I. 
TABLE I.

Material Properties Of Low CARbon Steel

\begin{tabular}{|c|l|c|}
\hline S. No & \multicolumn{1}{|c|}{ Properties } & Steel \\
\hline 1. & Density $\left(\mathrm{Kg} / \mathrm{m}^{3}\right)$ & 7,800 \\
\hline 2. & Young's Modulus (Mpa) & 210000 \\
\hline 3. & Yield Strength (Mpa) & 240 \\
\hline 4. & Tensile Ultimate Strength (Mpa) & 420 \\
\hline 5. & Poisson's Ratio & 0.3 \\
\hline
\end{tabular}

\section{STRESSES AND DEFORMATION CALCULATIONS OF LPG CYLINDER}

By Considering the LPG gas cylinder IS 3196, the vonmises stress and deformation are calculated manually based on the thin cylinder pressure vessel equations of deformation, circumferential, longitudinal and von-mises stress with the internal pressure, thickness and diameter of the cylinder.

Let,

$\mathrm{P}=$ Internal pressure of the $\mathrm{LPG}$ cylinder $=2.5 \mathrm{Mpa}$

$\mathrm{t}=$ Thickness of the LPG cylinder $=2.5 \mathrm{~mm}$

$\mathrm{d}=$ Inner diameter of the LPG cylinder $=300 \mathrm{~mm}$

A. Circumferential Stress of LPG Cylinder

$\sigma_{1}=\frac{P d}{2 t}$.

$\sigma_{1}=\frac{2.5 \times 300}{2 \times 2.5}=150 \mathrm{Mpa}$

B. Longitudinal Stress of LPG Cylinder

$\sigma_{2}=\frac{P d}{4 t}$.

$\sigma_{2}=\frac{2.5 \times 300}{4 \times 2.5}=75 \mathrm{Mpa}$

C. Deformation of LPG Cylinder

$\delta=\frac{\operatorname{Pr}^{2}(1-v)}{4 E t}$.

$\delta=\frac{2.5 \times 150^{2} \times(1-0.3)}{4 \times 210000 \times 2.5}=0.01875 \mathrm{~mm}$

By using above calculations, the values of the equations are used for comparing with the finite element values of ANSYS, for validating the software.

\section{Modelling AND Finite ELEMENT ANALYSIS}

\section{A. LPG Cylinder Model}

By considering IS 3196 LPG cylinder, all the different parts of the LPG cylinder are modelled in the SOLIDWORKS software by using different commands and all the individual parts of the LPG cylinder are assembled in the SOLIDWORKS software as shown in Fig. 4

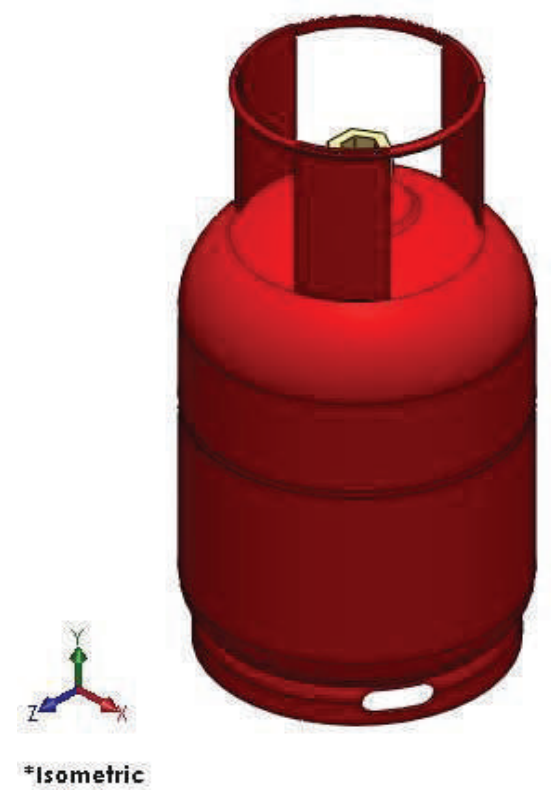

Figure 4. Assembled model of the LPG cylinder

\section{B. Elememt Type}

The element type used is SOLID 186. SOLID 186 is a higher order 3-D with 20-node having three degrees of freedom per node, solid element that exhibits quadratic displacement behavior. This element supports large deflections, plasticity, large strain capabilities, hyper elasticity, stress stiffening and creep.

\section{Meshing}

After assigning element type to the LPG cylinder, the created solid model is converted into IGES format and imported into ANSYS Workbench. Meshing is an important process of an analysis and it should be performed on the LPG cylinder model. Meshing is the process of dividing the created model in number of divisions or elements which consists of nodes. An automated mesh generation is as shown in Fig. 5.

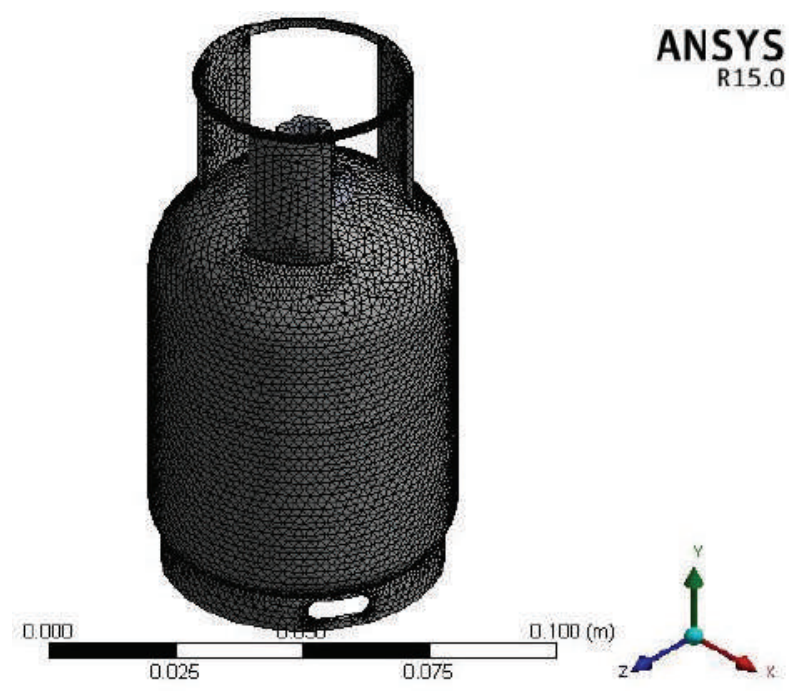

Figure 5. Meshing of LPG cylinder 
Meshing is applied by using automatic mesh. Under the mesh sizing, the meshing was set to fine mesh for accurate and precise results. Rather than using a fine mesh all over the components, coarse mesh was used on larger area and fine mesh was used at the area of stress concentration.

\section{Applying Loads}

In the analysis setting, fixed support is assigned to the base ring or foot ring of the LPG Cylinder, by assigning the fixed support the base ring is constrained in all degrees of freedom and it would withstand the forces acting on the LPG cylinder as shown in Fig. 6.

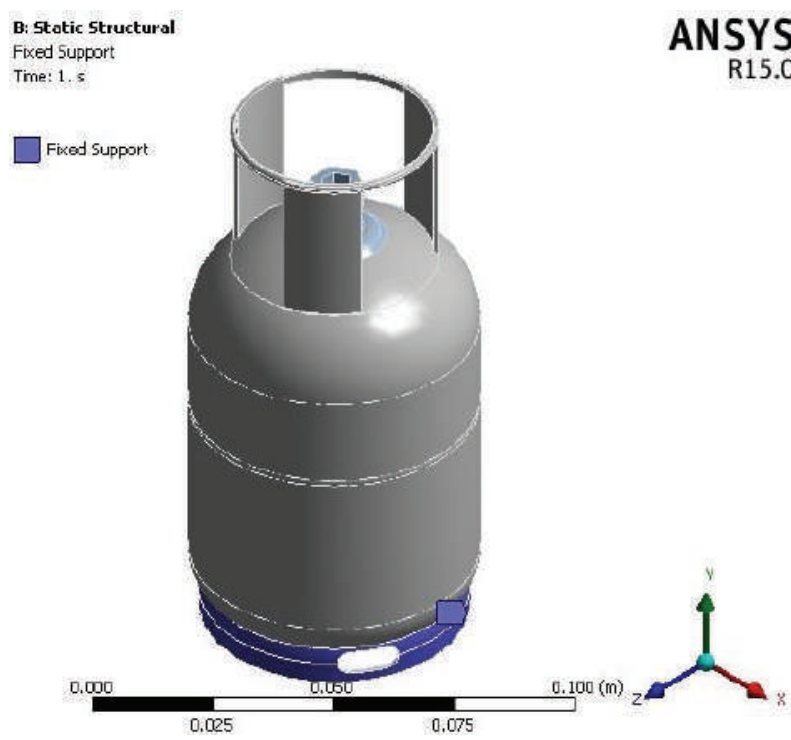

Figure 6. Fixing the base of LPG cylinder

The internal pressure of the fluid inside the LPG cylinder is greater than the atmospheric pressure. Average internal pressure inside the LPG cylinder is calculated. The internal pressure of $2.5 \mathrm{Mpa}$ is applied on the different internal parts of the LPG cylinder as shown in Fig. 7.

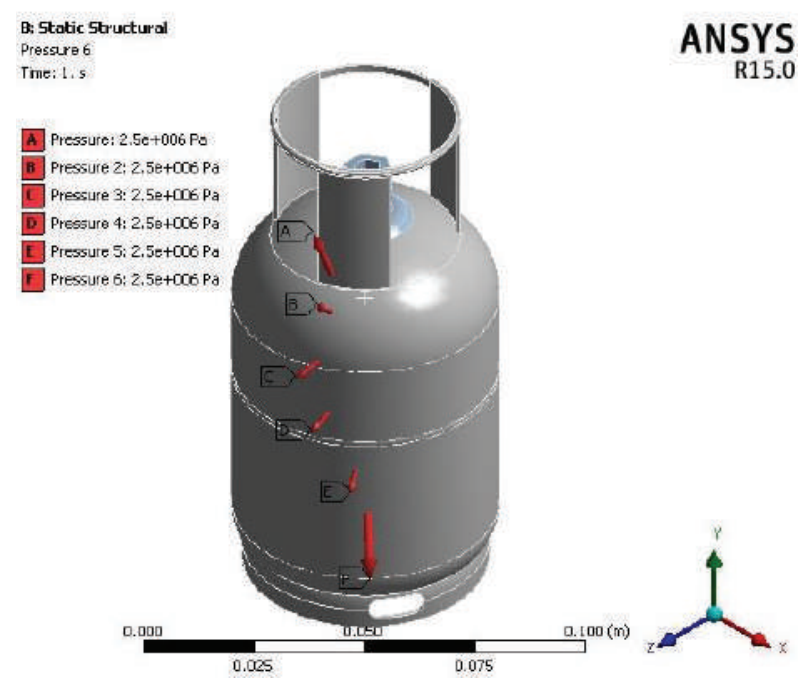

Figure 7. Applying internal pressure on LPG cylinder

\section{RESULTS AND DISCUSSIONS}

After fixing the base ring and applying the internal pressure of $2.5 \mathrm{Mpa}$ on the LPG cylinder in the ANSYS software. The following results were observed in the finite element analysis.

\section{A. Total Deformation of LPG Cylinder}

After performing the finite element analysis on the LPG cylinder model by applying the internal pressure on it, maximum total deformation of $0.0102 \mathrm{~mm}$ is observed from the Fig. 8.

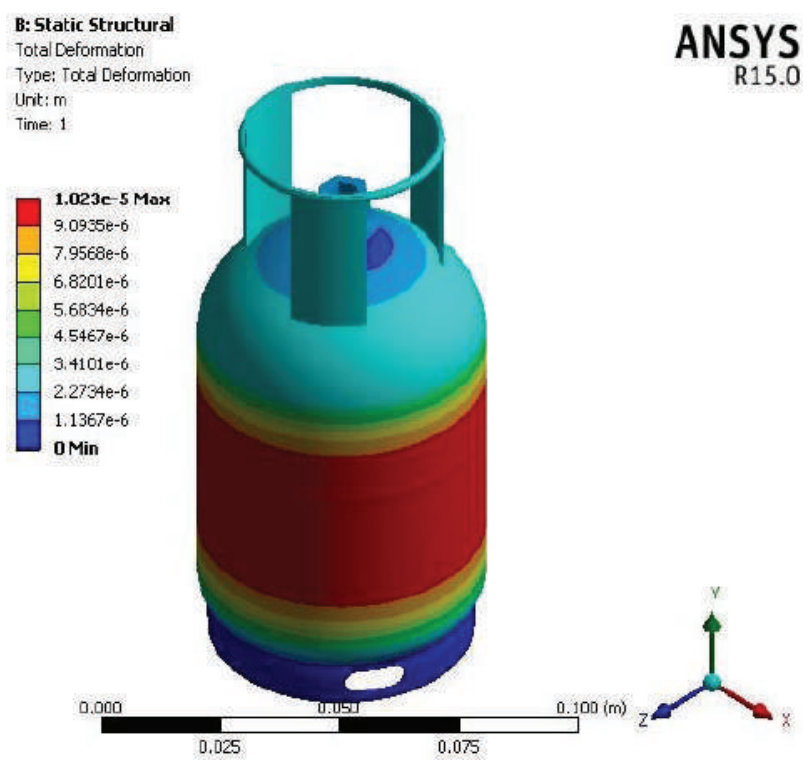

Figure 8. Total deformation of LPG cylinder

\section{B. Von-mises Stress of LPG Cylinder}

After performing finite element analysis on the LPG cylinder by applying the internal pressure on it, maximum von-mises stress of $74.96 \mathrm{Mpa}$ is observed in the LPG cylinder from the Fig. 9.

B: Static Structural
Equivalert Stress

Type: Equvalent (won-Mises) stress

Unt: $\mathrm{Pa}$

ANSYS

Time: 1
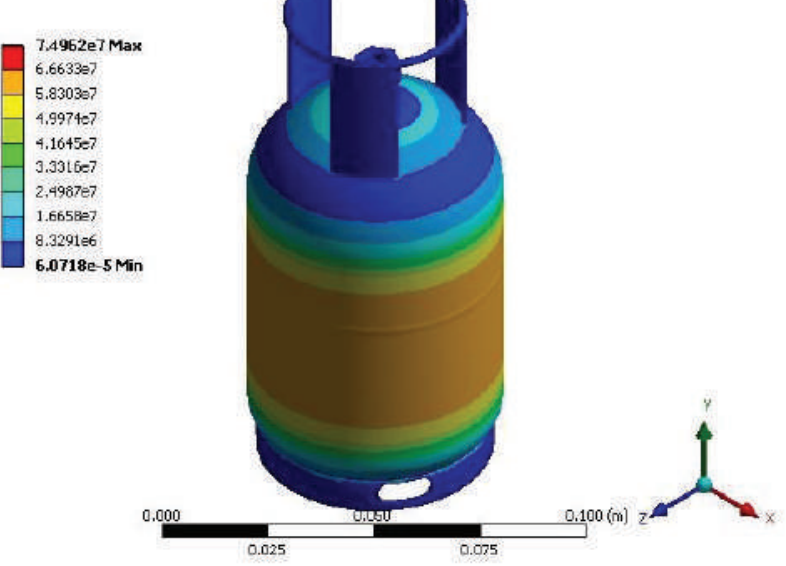

Figure 9. Von-mises stress of LPG cylinder 
For validating the finite element values, it is compared with the references. In reference [8], the LPG cylinder is subjected to internal pressure only on the top dome of the cylinder, so it is not considered.

TABLE II.

COMPARISON OF FE VALUES With HAND CALCULATIONS

\begin{tabular}{|c|c|c|c|}
\hline Name & $\begin{array}{c}\text { Finite Element } \\
\text { Values }\end{array}$ & $\begin{array}{c}\text { Hand Calculation } \\
\text { Values }\end{array}$ & Reference [1] \\
\hline $\begin{array}{c}\text { Von-mises Stress } \\
\text { (Mpa) }\end{array}$ & 74.96 & 75 & 75.45 \\
\hline $\begin{array}{c}\text { Total Deformation } \\
(\mathrm{mm})\end{array}$ & 0.0102 & 0.0187 & 0.02 \\
\hline
\end{tabular}

The comparison of finite element values and the manual calculations of the domestic LPG cylinder with the reference [1] are shown in the Table II. The values of the LPG cylinder are under safe limits.

\section{CONCLUSiOnS}

In this paper, a LPG cylinder which is used for storing the fluids is modelled in SOLIDWORKS software and a finite element analysis of a LPG cylinder with an internal pressure of $2.5 \mathrm{Mpa}$ is performed by using ANSYS software. The total deformation and von-mises stress of the LPG cylinder are analysed and compared with the thin cylindrical pressure equations for von-mises and deformation values. For validating the software, the finite element results are compared with the thin pressure vessel equations and the reference [1]. From the results, it is observed that the maximum deformation and the von-mises stress of the LPG cylinder are within the safer limits. Therefore, modelled
LPG cylinder is safe to use and has long life to resists the internal pressure of the fluid.

\section{REFERENCES}

[1] Alok Tom, Geo Mathew Pius, George Joseph, Jacob Jose and Mathew J Joseph, "Design and analysis of LPG cylinder," International Journal of Engineering and Applied Sciences, vol. 6, pp. 17-31, 2014.

[2] Ch. Bandhavi, and N. Amar Nageswara Rao, "Design and analysis of LPG cylinder using ANSYS software," International Journal of Mathematical Sciences, Technology and Humanities, vol. 58, pp. 635-646, 2012.

[3] Moyahabo Bradely Moketla and Mukul Shukla, "Design and finite element analysis of FRP LPG cylinder," International Journal of Instrumentation, control and Automation, vol. 1, pp. 121-124, 2012.

[4] A. Somaiah, G. Sarat Raju and U. S. P. Rao, "Design procedure of composite LPG cylinder," International Journal of Application or Innovation in Engineering and Management, vol. 5, pp. 93-99, November 2016.

[5] Remya Gopi and Beena B R, "Finite element analysis of GFRP LPG cylinder," International Journal of Engineering Development and Research, vol. 3, pp. 642-649, 2015.

[6] Kattera Sai Krishna, M. Pramod Reddy and P. Sampath Rao, "Modelling and analysis of metal and fiber reinforced polymer LPG cylinder," International Journal and Magazine of Engineering, Technology, Management and Research, vol. 3, pp. 164-168, September 2016.

[7] T. Ashok and A. Harikrishna, "Analysis of lpg cylinder using composite material," IOSR Journal of Mechanical and Civil Engineering, vol. 9, pp. 33-42, September 2013.

[8] Laxmikant D. Rangari, P. M. Zode and P. G. Mehar, "Stress analysis of lpg cylinder using ansys software," International Journal of Engineering Research and Applications, vol. 2, pp. 2278-2281, July 2012. 